\title{
A Novel Fluorimetric Method to Evaluate Red Wine Antioxidant Activity
}

\author{
Franco Tubaro1, Roberto Pizzuto², Gennaro Raimo², Gianluca Paventi²* \\ 1 Department of Agricultural, Food, Environmental and Animal Sciences, University of Udine, Via delle Scienze, 206, Udine, Italy \\ 2 Department of Medicine and Health Sciences "V. Tiberio", University of Molise, Via de Sanctis, Campobasso, Italy \\ ${ }^{*}$ Corresponding author, e-mail: paventi@unimol.it
}

Received: 07 March 2018, Accepted: 20 June 2018, Published online: 17 July 2018

\begin{abstract}
In the light of the increasing use of red wine in the diet, due to its antioxidant properties, the availability of a simple and fast method to assay the antioxidant activity of this beverage is needed. Here we measured wine antioxidant capacity (WAC) via "crocin bleaching test", wine polyphenol content (WPC), via Folin Ciocalteu method, and fluorimetric response (WF) of 13 Italian red wines. A fairly good correlation between WAC and WF $(R=0.82)$ was found, thus validating the fluorimetric method as a simple, fast and cheap method to evaluate the antioxidant activity of red wines.
\end{abstract}

Keywords

red wine, antioxidant activity, fluorescence, polyphenols, crocin bleaching

\section{Introduction}

In discussing health attributes of wine the antioxidant capacity emerges as a major element $[1,2]$. Flavonoids make up the bulk of the phenol content of wine, and there is wide evidence for prophylactic and therapeutic effects of these micro nutrients in a variety of human diseases [3, 4], although the absorption and metabolism require further investigation [5-8]. There is however evidence for the transfer of antioxidant capacity from wine to plasma [9-13]. On the other hand, wine antioxidants could play a protective role, independently from bioavailability, in reducing the content of peroxides of foods, and thus decreasing the amount assumed. Indeed it has been observed, using a chemiluminescent procedure, that lipid peroxides are detectable in plasma following a fat meal, and that the concentration is lower if the meal is assumed with red wine $[14,15]$. Moreover, epidemiological studies have shown that moderate intake of red wine reduces incident of a variety of disease including coronary heart diseases [16]. In a pilot study it was shown that moderate red wine consumption, as a supplement to the standard treatment, reduces oxidative stress in patients recovering from an acute coronary syndrome [17]. It is assumed that beneficial effects of red wine are due to the antioxidant properties of its polyphenolic compounds which act in vivo against the reactive oxygen species (ROS) [18] which are responsible of the oxidative stress, one of the initial steps of many chronic diseases including cardiovascular diseases, atherosclerosis, diabetes, cancer etc. [19, 20].

Thus, in evaluating the quality of wine, in addition to flavour, colour and fragrance, the antioxidant activity should also be considered [21-24], as also shown by the increasing number of papers dealing with this topic.

Indeed plenty of analytical methods were developed to assess the antioxidant activity of beverage and food. In particular, in addition to thiobarbituric acid [25] and thiocyanate [26] methods, a variety of methods are available including some based on free radical production as 4-amino-N,N-dimethyl aniline dihydrochloride (DMPD) [27], diphenylpicryl-hydrazyl (DPPH) [28], 2,2'-azino-bis(3ethyl) benzotiazoline-6-sulphonic acid (ABTS) [29], other on crocin bleaching [30,31], electron spin resonance [32] and on measurement of Oxygen Radical Absorbance Capacity (ORAC) [33]. Commonly, when dealing with peroxidation-driving peroxyl radicals the antioxidant activity is monitored as the "chain breaking antioxidant capacity" (for ref see [34]). Differently, a competition kinetic procedure can be used by comparing the antioxidant activity of the sample under study with the antioxidant activity of either tocopherol or its water soluble analogue Trolox C [35, 36].

As known, fluorimetric measurements have been successfully applied to food and, more recently, the development 
of front-face fluorescence takes advantage of fluorimetric properties of wine and other beverages [37, 38]. However, this technique is more time-consuming and not so easy to perform in the absence of qualified personnel, thus making these analyses difficult to apply routinely, especially for little wine makers. On the contrary, an easy, time and money saving measurement of wine antioxidant capacity could be extremely interesting for this kind of producers.

In this paper we measured the fluorescence of 13 Italian red wines; the fairly good correlation between red wine fluorescence values at $310 \mathrm{~nm}$ (280 nm excitation) and their antioxidant activity, measured by crocin bleaching test as Trolox $\mathrm{C}$ equivalents suggests a simple, fast and cheap novel fluorimetric method to evaluate the red wine antioxidant activity.

\section{Materials and Methods}

\subsection{Wine samples and origin}

13 red wines from different geographical areas (Regions) of Italy were purchased from local store: Grignolino (Piemonte), Trabucco (Molise), Cirò (Calabria), Frappato (Sicilia), Bardolino (Veneto), Tintilia (Molise), Primula (Trentino), Rosso di Montalcino (Toscana), Il Moro (Toscana), Montepulciano (Toscana), Cannonau (Sardegna), Chianti (Toscana), Merlot (Veneto).

\subsection{Materials}

2,2'-azobis (2-amidinopropane) dihydrochloride (ABAP), Folin-Ciocalteu reagent $2.0 \mathrm{~N}$, Trolox C, catechin and gallic acid were from Sigma-Aldrich; all solvents (HPLC grade) and common reagents were from Merck. Saffron was bought from the local market.

Crocin was isolated from saffron by methanol extraction as in [39]. The concentration of crocin was determined photometrically $\left(\varepsilon_{440}=1.33 \times 10^{5} \mathrm{M}^{-1} \mathrm{~cm}^{-1}\right)$ by using UV-VIS with a Spectrophotometer (Varian Cary 50).

\subsection{The competition kinetics test}

Thermal decomposition of ABAP generates carbon centered radicals, which react with molecular oxygen yielding peroxyl radicals, in a reaction controlled by diffusion [30, 31]. These radicals bleach the carotenoid crocin, and the rate is followed as a specific decrease of absorbance at $440 \mathrm{~nm}[31,39]$. In the presence of another radical scavenger, competing with crocin for the reaction with peroxyl radicals, the bleaching rate slows down, consistently with the rate constant of the reaction between the scavenger and peroxyl radicals (see Scheme 1).
Unless otherwise stated, the reaction mixture contained in $2.0 \mathrm{~mL}$ of a $0.1 \mathrm{M}$ phosphate buffer $\mathrm{pH} 7.0$ (buffer A), $10 \mu \mathrm{M}$ crocin (from a $0.6 \mathrm{mM}$ solution in methanol) and increasing amounts of wine or the solution containing the antioxidant to be analysed. The reaction started by adding 12.5 mM ABAP (withdrawn from a fresh 0.5 M solution in buffer $\mathrm{A}$ kept at $0^{\circ} \mathrm{C}$ ) to the complete reaction mixture equilibrated at $40^{\circ} \mathrm{C}$.

The bleaching rate of crocin became linear approximately one or two min after the addition of the diazocompound and was usually recorded for $10 \mathrm{~min}$. Only the last 5 min were considered for calculations.

Blanks without crocin were routinely run to rule out spectral interferences between the sample under analysis and crocin.

A mathematical transformation of the competition kinetics equation [31] yields the equation:

$V_{0} / V=\left(k_{c}[C]+k_{a}[A]\right) / k_{c}[C]=1+k_{a} / k_{c} \times[A] /[C]$

where:

$V_{0}=$ basal bleaching rate of crocin with peroxyl radicals;

$V=$ bleaching rate of crocin with peroxyl radicals in the presence of the antioxidant;

$k_{c}=$ rate constant of the reaction between peroxyl radical and crocin;

$k_{a}=$ rate constant of the reaction between peroxyl radical and antioxidant;

$[C]=$ concentration of crocin;

$[A]=$ concentration of antioxidant.

The value of $k_{a} / k_{c}$, corresponding to the slope of the linear regression of the plot of $[A] /[C]$ vs. $V_{0} / V$, indicates the relative capacity of the compound under analysis to interact with peroxyl radicals.

The described kinetic procedure, set up for the analysis of the antioxidant capacity of single molecules, may be extended to complex mixtures where neither the concentration of antioxidants present nor their actual number are known. Wine and other food samples are of this kind. In fact, the overall antioxidant capacity of a complex mixture, corresponds to the sum of each antioxidant concentration multiplied by its rate constant for the interaction with a peroxyl radical [31]. Moreover, those compounds possibly present in the mixture, which upon interaction with the peroxyl radical produce new radicals and therefore are reactive with crocin, will affect the crocin bleaching rate, decreasing the antioxidant capability of the mixture, as measured by the kinetic test. Thus, from the 
<smiles>CC(C)(N=NC(C)(C)C(=N)N)C(=N)N</smiles>

(ABAP)

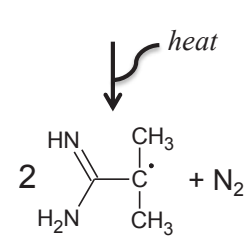

thermal

decomposition of $A B A P$<smiles>CCCCCCCCCO</smiles>

\section{Peroxyl}

radicals

formation

$\left(\mathrm{ROO}^{\circ}\right)$

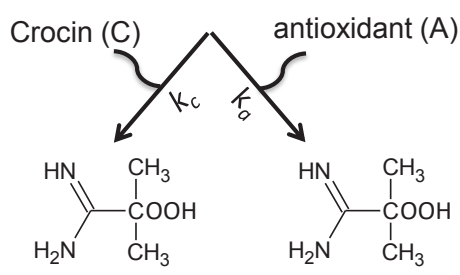

Crocin-antioxidant competition in reacting with peroxyl radicals

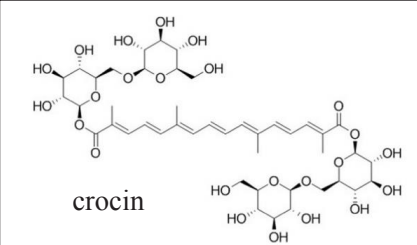

Standard:

$\underline{W A C}$<smiles>Cc1c(C)c2c(c(C)c1O)CCC(C)(C(=O)O)O2</smiles>
trolox c

$\underline{W F}$<smiles>Oc1cc(O)c2c(c1)OC(c1ccc(O)c(O)c1)C(O)C2</smiles>

$(+)$-catechin

$\underline{W P C}$<smiles>O=C(O)c1cc(O)c(O)c(O)c1</smiles>

gallic acid

Scheme 1 Summary of reactions and chemical structures of compounds used in this work.

kinetics of crocin bleaching in the presence of a mixture of compounds, a value $k_{a} \times[A]$ can be calculated, where $[A]$ is the molar concentration of the theoretical antioxidant and $k_{a}$ is the rate constant for its interaction with peroxyl radicals. The $k_{a} \times[A]$ value accounts for the summed effect of all antioxidant and pro-oxidant agents present in the mixture which interact with free radicals.

The ratio between $k_{a} / k_{c}$ of the mixture of antioxidants and $k_{a} / k_{c}$ of Trolox $\mathrm{C}$, expressed as "Trolox $\mathrm{C}$ equivalents", accounted for the antioxidant capacity of the analyzed sample. According to the competition kinetics, by plotting the bleaching rates obtained using the solution under analysis, a ratio $\mathrm{ka} / \mathrm{kc}$ is obtained. By dividing this value by the $k_{a} / k_{c}$ of Trolox $\mathrm{C}$, a millimolar concentration of Trolox $\mathrm{C}$ accounting for the unknown solution antioxidant capacity is calculated $[30,36]$.

\subsection{Wine sample preparation}

To measure the antioxidant capacity by kinetic competition test, red wines aliquots were taken from closed bottles with a long stainless steel needle and diluted 1:10 with phosphate buffer $\mathrm{pH} 7.0$.

\subsection{Spectroscopic analyses}

Spectrophotometric and fluorimetric analyses were performed with a Jasco V-570 spectrophotometer and FP-750 spectrofluorimeter, respectively.

Wine aliquots (5-40 $\mu$ l range) were taken as in 2.4 and added with distilled water up to $2 \mathrm{~mL}$ in quartz cuvettes. Absorption spectra (from 250 to $600 \mathrm{~nm}$ ) and fluorescence emission spectra (from 290 to $500 \mathrm{~nm}, \lambda_{\text {ex }} 280 \mathrm{~nm}$ ) were recorded, in triplicate. All analyses were carried out immediately after wine sampling (less than 3 minutes) in order to limit oxidation reactions. For fluorimetric analysis reported in Table 1 and Figs. 4 and $6,10 \mu 1$ of wine sample were used in order to limit self-absorption; moreover, to rule out any instrumental variability intrinsic to the technique, a standard of catechin was used and wine fluorescence values were also expressed as catechin equivalents. Linearity between absorbance $(280 \mathrm{~nm})$ and fluorescence ( 280 / $310 \mathrm{~nm}$ ) values vs. wine concentration was also checked (not shown).

Correlations among fluorescence values, antioxidant capacity and polyphenol content of wines were assessed through Pearson's correlation coefficients setting 
significance threshold at the $\mathrm{P}<0.05$ level and $\mathrm{P}<0.01$ levels. All statistical tests were performed using the software package SPSS (15.0 version).

\subsection{Polyphenol content detection}

Folin-Ciocalteu reagent is frequently used to evaluate phenols and is utterly described by official analytical methods [40]. The reduction of phenolic substances by the Folin-Ciocalteu reagent involves reaction with a mixture of phosphotungstic acid and phosphomolybdic acid and subsequent spectrophotometric comparison at $765 \mathrm{~nm}$. Gallic acid has been used as a standard thus the results were expressed as gallic acid equivalents. The method lacks specificity, as different phenolic substances can have different molar absorptivities. In addition, it also reacts with many other substances, such as sugars [41].

\section{Results and Discussion}

Both spectroscopic and fluorimetric measurement of solutions are simple, fast and relatively cheap needing only the experimental equipment. In the light of this and since wine contains a variety of chromophore, we compared the optical properties of diluted solutions of 13 Italian red wines. As expected, due to the presence of polyphenols, all these wines show absorbance maximum peak at $280 \mathrm{~nm}$ (Fig. 1). However, all the investigated wines differed one from another with respect to their absorption spectra, thus showing that spectroscopic properties could be used to characterize each wine. In order to gain further insight into this point, the fluorescence properties of each wine were investigated. In a first set of experiments, fluorescence spectra were obtained by using $280 \mathrm{~nm}$ as excitation wavelength. The investigated wines were found to differ one from another with respect to both the numbers (and wavelength) of peaks and fluorescence intensity (Fig. 2). As reported in introduction, this aspect was welldeveloped in front-face fluorescent measurements [37, 38]. On the other hand, besides the variability in fluorescence profile, all samples showed a peak at $310 \mathrm{~nm}$. Thus, we tried to ascertain whether this spectroscopic property could somehow mirror the red wine antioxidant activity. To achieve this, comparisons were made among wine fluorescence $\left(\lambda_{\text {ex }} 280 \mathrm{~nm}, \lambda_{\text {em }} 310 \mathrm{~nm}\right)(\mathrm{WF})$, wine total polyphenol content (WPC) and wine antioxidant capacity (WAC) measured by "crocin bleaching test" as in [30].

WPC and WAC were considered since both of them are used to measure the wine antioxidant activity having the latter the advantage to monitor the effective antioxidant

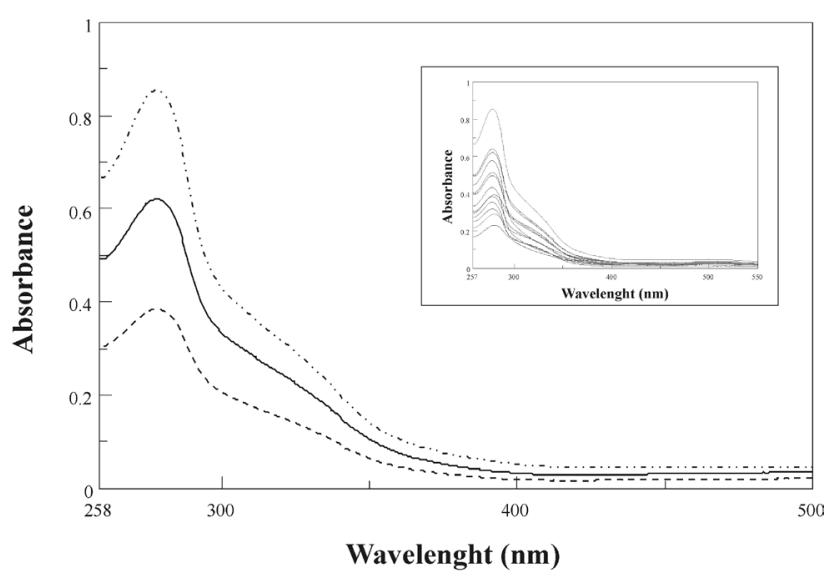

Fig. 1 Absorption spectra of different Italian red wines. Aliquots (40 $\mu \mathrm{l}$ ) of each sample were added to water (final volume $2 \mathrm{ml}$ ) and the absorbance was measured in 250-550 $\mathrm{nm}$ range (see text for details). For more clarity, figure reports the absorption spectra of only three wines: Cirò (.--.), Cannonau (----) and Frappato (---), while the absorption spectra of all wines are reported in the inset.

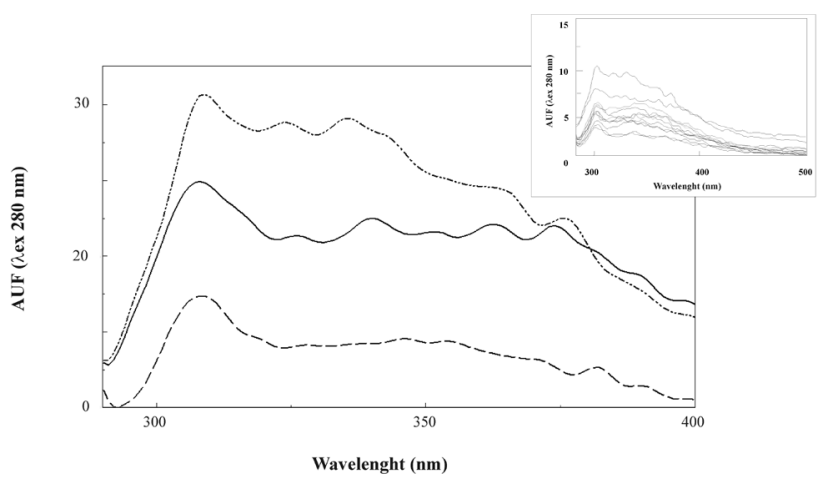

Fig. 2 Fluorescence spectra of different Italian red wines. Aliquots (40 $\mu \mathrm{l}$ ) of each sample were added to water (final volume $2 \mathrm{ml}$ ) and emission fluorescence $\left(\lambda_{\text {ex }} 280 \mathrm{~nm}\right)$ was measured in $290-500 \mathrm{~nm}$ range (see text for details). For more clarity, figure reports the spectra of three wines showing high (Cirò, ..-..), medium (Cannonau, -----) and low (Frappato, ---) fluorescence values. In the inset, spectra of all wines (obtained diluting $15 \mu \mathrm{l}$ of each wine in $2 \mathrm{ml}$ final volume) were reported. AUF: arbitrary units of fluorescence.

activity rather than the content of the polyphenol and perhaps unknown compounds.

WAC was calculated from the slope of the fitting of the kinetic equation (for detail see [31]):

$V_{0} / V=1+k_{\text {PseudoTrolox }} / k_{c} \times[$ PseudoTrolox $] /[C]$

where $k_{\text {PseudoTrolox }}$ is the rate constant for the interaction of Pseudo Trolox with peroxyl radicals. Since: $k_{a} \times[A]=$ $k_{\text {PseudoTrolox }} \times$ [Pseudo Trolox $]=k_{\text {Trolox }} \times$ [Trolox $]$ and since $k_{\text {Trolox }}$ is known from independent measurements $(0.76 \pm 0.03)$, the ratio [PseudoTrolox]/[Trolox] can be calculated. This ratio indicates the relative capacity of the 
sample vs. Trolox to produce the same antioxidant effect. If a $1 \mathrm{mM}$ solution of Trolox is used as a reference compound, a mM concentration of Pseudo-Trolox is obtained.

In Fig. 3 the plots $[A] /[C]$ vs. $V_{0} / V$ of Trolox $\mathrm{C}$ and of two different wines are shown.

WPC was determined as reported in methods.

A typical experiment in which WF, WPC and WAC were determined is shown in Table 1. In this case, all the measurements have been carried out within 24 hours. Being fluorescence emission highly dependent on instrumental features (sensitivity, intensity of incident light, lamp age etc.), we measured a calibration curve with a standard of catechin and reported WF as catechin equivalents. Similar experiments carried out after weeks / months were in a fairly good agreement with data reported in Table 1. Except for "Bardolino" and "Frappato" (which also showed lowest fluorescence values), we measured an average high WAC in all wine samples, in fairly good agreement with what reported in other papers [42-45] as also occurs for WPC, although we measured values a little bit lower than ones reported in other papers for some Italian red wines [45, 46]. Unfortunately, due to technical reasons dependent on the experimental equipment, it was not possible to carry out a statistical analysis over 1 year. Nonetheless, the differences conformed to the same model.

In order to establish the correlation among the investigated parameters, Table 1 data for each wine were plotted as WF vs. WAC (Fig. 4), WPC vs. WAC (Fig. 5) and WF vs. WPC (Fig. 6).

Interestingly, a significant $(\mathrm{p}<0.01)$ good correlation $(\mathrm{R}=0.82$ ) between WF and WAC was found (Fig. 4),

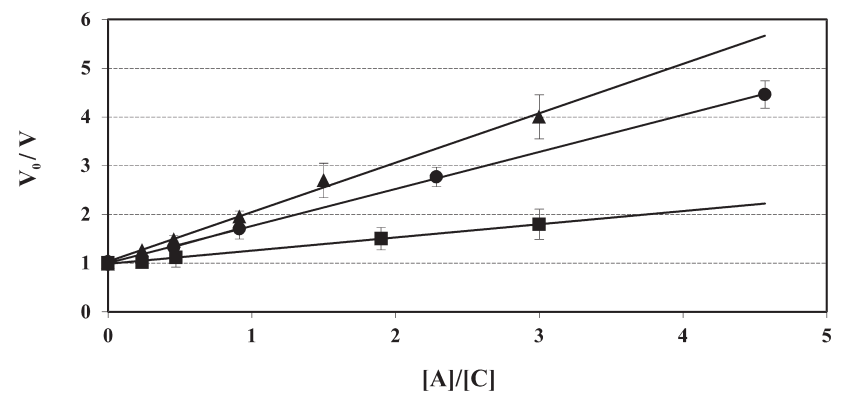

Fig. 3 Analysis of antioxidant capacity of wines by competition kinetics. An example of plot of competition kinetics equation is reported. $V_{0} / V$ is the ratio between the crocin bleaching rate in the absence and in the presence of an antioxidant. $[A] /[C]$ is the ratio between the antioxidant and crocin concentration. $\bullet$ Trolox $(\mathrm{y}=0.76 \mathrm{x}$ $+1.00 ; \mathrm{R}=0.99) ; \boldsymbol{\Delta}$ Cirò $(\mathrm{y}=1.01 \mathrm{x}+1.03 ; \mathrm{R}=0.99) ; \boldsymbol{~}$ Bardolino $(y=0.27 x+0.99 ; R=0.99)$. The data are expressed as means $\pm S E$ obtained in three different measurements.
Table 1 Antioxidant activity (WAC), fluorescence (WF) and polyphenols content (WPC) of red wines. Analyses were carried out as described in Methods and in [25]. The value of $k_{a} / k_{c}$, corresponds to the slope of the linear regression of the plot of $[A] /[C]$ vs. $V_{0} / V$, where $V_{0}$ and $V$ are the rates of crocin bleaching in the presence and in the absence of other antioxidants respectively, $[A]$ is the concentration of the wine antioxidants as PseudoTrolox and $[C]$ is the concentration of crocin, accounts for the antioxidant capacity. Trolox $\mathrm{C}$ equivalents were calculated by dividing

the $k_{a} / k_{c}$ of wines by the $k_{a} / k_{c}$ of Trolox C. WF (10 $\mu 1$ sample) was measured as described in Fig. 2, and reported as catechin equivalents.

\begin{tabular}{lccc}
\hline Wine name & $\begin{array}{c}\text { WAC } \\
\text { Trolox eq. } \\
(\mathbf{m M})\end{array}$ & $\begin{array}{c}\text { WF } \\
\text { Catechin eq. } \\
(\mathbf{m g} / \mathbf{l})\end{array}$ & $\begin{array}{c}\text { WPC } \\
\text { Gallic ac. eq. } \\
(\mathbf{m g} / \mathbf{l})\end{array}$ \\
\hline Grignolino & 9.24 & 220.4 & 1190 \\
Trabucco & 9.14 & 219.3 & 1150 \\
Cirò & 13.58 & 315.8 & 1550 \\
Frappato & 4.31 & 164.5 & 1100 \\
Bardolino & 3.12 & 115.1 & 150 \\
Tintilia & 10.23 & 246.7 & 1550 \\
Primula & 8.37 & 185.3 & 1200 \\
Rosso di & 9.07 & 197.4 & 1400 \\
Montalcino & 9.79 & 170.0 & 1600 \\
Il Moro & 9.72 & 183.1 & 1500 \\
Montepulciano & 9.40 & 251.1 & 1220 \\
Cannonau & 8.67 & 187.5 & 700 \\
Chianti & 10.19 & 191.9 & 1280 \\
Merlot & & & \\
\hline & & & \\
\hline
\end{tabular}

which results better than that obtained between WPC vs. WAC $(\mathrm{R}=0.76, \mathrm{p}<0.01$, Fig. 5).

This shows that, under the conditions reported above, measurements of red wine fluorescence mirror their antioxidant activity. The ratio WF / WPC was even lower

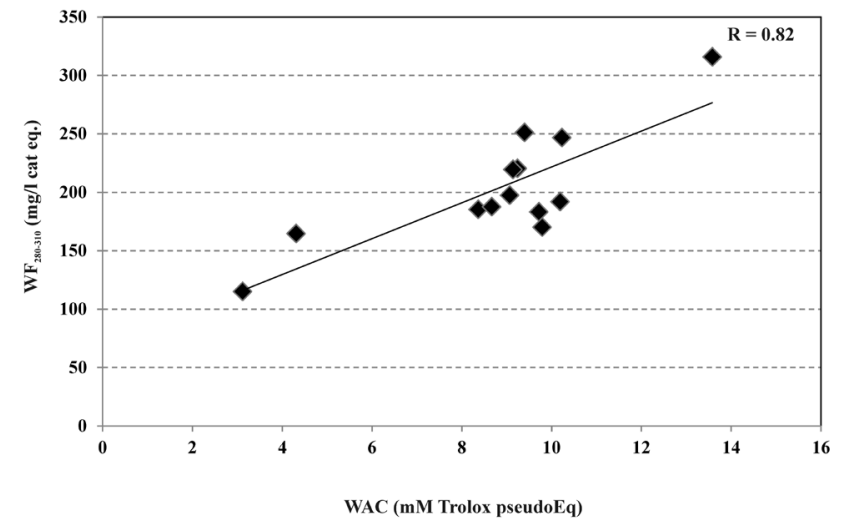

Fig. 4 Regression curve between antioxidant capacity (WAC) and wine fluorescence (WF). The same 13 wines were analysed in both ways, and the correlation between emission at $310 \mathrm{~nm}$ (see text for details) reported as catechin equivalents (mg/l) and equivalents of Trolox (mM) was calculated $(\mathrm{y}=15.33 \mathrm{x}+68.27 ; \mathrm{R}=0.82 ; \mathrm{p}<0.01)$. 


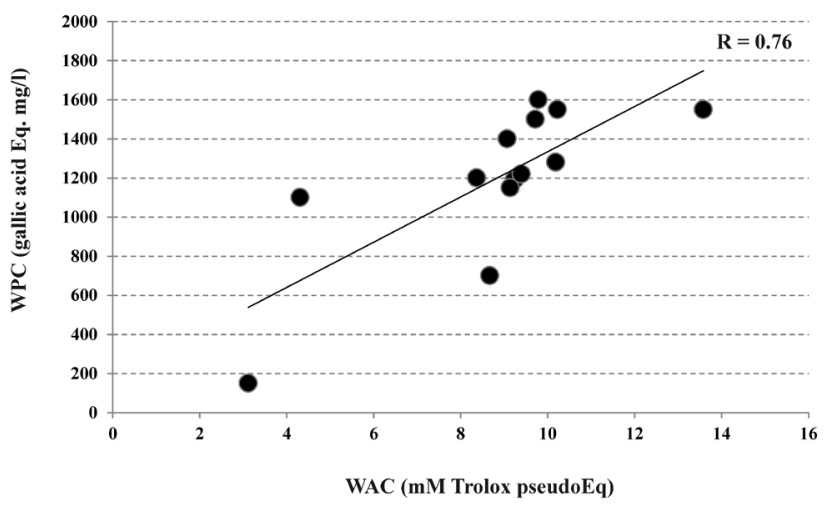

Fig. 5 Regression curve between wine polyphenol content (WPC) and antioxidant capacity (WAC). The antioxidant activity was measured by the kinetic competition test (see text for details). The total phenol content was determined by Folin-Ciocalteu reagent and the correlation was calculated $(y=115.6 x+178.15 ; R=0.76 ; p<0.01)$.

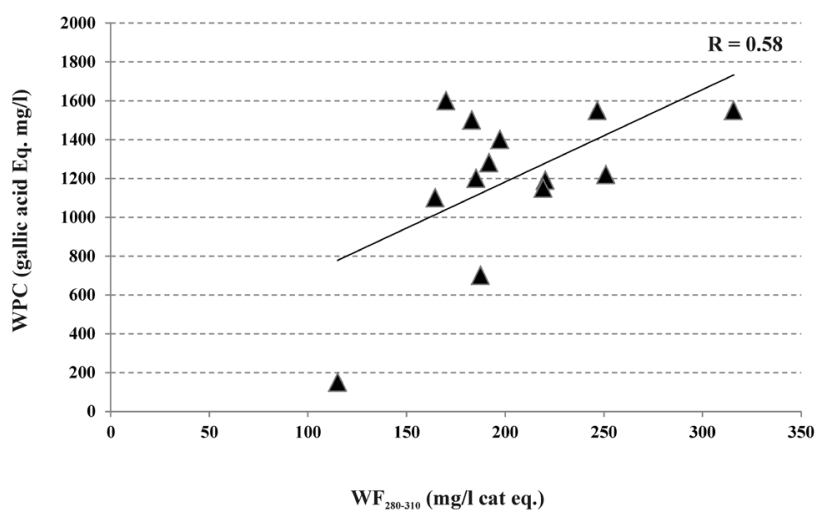

Fig. 6 Regression curve between polyphenol content (WPC) and fluorescence (WF) of wine. The same 13 wines were analyzed in both ways, and the correlation between emission at $310 \mathrm{~nm}$ (see text for details) and total phenol content was determined $(y=4.75 x+230.62$;

$$
\mathrm{R}=0.58 ; \mathrm{p}<0.05)
$$

$(\mathrm{R}=0.58, \mathrm{p}<0.05$, Fig. 6) demonstrating that the fluorimetric approach on wine differs from WPC since the substances responsible for the antioxidant capacity probably are not only flavonoids in the checked wines.

In this case only red wines were investigated, but it could be that similar analysis can be applied to other

\section{References}

[1] Lindberg, M. L., Amsterdam, E. A. "Alcohol, Wine, and Cardiovascular Health", Clinical Cardiology, 31(8), pp. 347-351, 2008.

https://doi.org/10.1002/clc.20263

[2] Ursini, F., Tubaro, F., Rong, J., Sevanian, A. "Optimization of Nutrition: Polyphenols and Vascular Protection", Nutrition Reviews, 57(8), pp. 241-249, 1999.

https://doi.org/10.1111/j.1753-4887.1999.tb06951.x types of samples showing the same features. Flavonoids containing foods are good candidates for such an investigation.

Thus, here we show that the evaluation of antioxidant activity of red wines, and perhaps of other beverages, can be performed simply by measuring the fluorescence emission of diluted samples. The method strategy involves: i) investigation of photometric / fluorimetric of the sample; ii) identification of the absorbance / fluorimetric response and iii) comparison of these data with those obtained by traditional methods. Moreover, a standardization of this procedure can be made routinely by measuring simultaneously a catechin standard calibration curve, in order to rule out any instrumental variation. This novel method cannot substitute the more informative, but more complex, spectroscopic one as front-face fluorescence in the analyses of wine, especially in their characterization [38]. However, the sound correlation obtained here between spectroscopic data and those traditionally obtained clearly shows that this fluorimetric approach can be an extremely simple, fast and relatively cheap way for wine antioxidant determination. This simplicity makes the method as a routinely tool, not restricted to big wine companies, probably sound to investigate also the effects of technological treatment during wine preparation and aging.

\section{Conclusion}

Results reported here clearly show that fluorescence of diluted untreated samples of red wines used in this study mirrors their antioxidant capacity, thus suggesting this easy and (relative) cheap analysis as a promising tool for the wine industry.

\section{Acknowledgement}

This work was partially financed by an internal fund of Department of Medicine and Health Sciences "V. Tiberio", University of Molise.

[3] Corder, R., Mullen, W., Khan, N. Q., Marks, S. C., Wood, E. G., Carrier, M. J., Crozier, A. "Oenology: Red wine procyanidins and vascular health", Nature, 444(7119), p. 566, 2006. https://doi.org/10.1038/444566a

[4] Masella, R., Varì, R., D'Archivio, M., Di Benedetto, R., Matarrese, P., Malorni, W., Scazzocchio, B., Giovannini, C. "Extra Virgin Olive Oil Biophenols Inhibit Cell-Mediated Oxidation of LDL by Increasing the mRNA Transcription of Glutathione-Related Enzymes", The Journal of Nutrition, 134(4), pp. 785-791, 2004. https://doi.org/10.1093/jn/134.4.785 
[5] Halliwell, B., Walsh, G. P. "Antioxidants in wine", The Lancet, 341(8859), p. 1538, 1993.

https://doi.org/10.1016/0140-6736(93)90677-9

[6] Halliwell, B., Rafter, J., Jenner, A. "Health promotion by flavonoids, tocopherols, tocotrienols, and other phenols: direct or indirect effects? Antioxidant or not?", The American Journal of Clinical Nutrition, 81(1), pp. 268S-276S, 2005.

https://doi.org/10.1093/ajen/81.1.268S

[7] Paganga, G., Miller, N., Rice-Evans, C. A. "The polyphenolic content of fruit and vegetables and their antioxidant activities. What does a serving constitute?", Free Radical Research, 30(2), pp. 153-162, 1999.

https://doi.org/10.1080/10715769900300161

[8] Fernandes, I., Pérez-Gregorio, R., Soares, S., Mateus, N., de Freitas, V. "Wine Flavonoids in Health and Disease Prevention", Molecules, 22(2), pp. 292-321, 2017.

https://doi.org/10.3390/molecules22020292

[9] Renaud, S., de Lorgeril, M. "Wine, alcohol, platelets, and the French paradox for coronary heart disease", The Lancet,-339(8808), pp. 1523-1526, 1992.

https://doi.org/10.1016/0140-6736(92)91277-F

[10] Auger, C., Teissedre, P.-L., Gérain, P., Lequeux, N., Bornet, A., Serisier, S., Besançon, P., Caporiccio, B., Cristol, J.-P., Rouanet, J.-M. "Dietary Wine Phenolics Catechin, Quercetin, and Resveratrol Efficiently Protect Hypercholesterolemic Hamsters against Aortic Fatty Streak Accumulation", Journal of Agricultural and Food Chemistry, 53(6), pp. 2015-2021, 2005. https://doi.org/10.1021/jf048177q

[11] Dell'Agli, M., Buscialà, A., Bosisio, E. "Vascular effects of wine polyphenols", Cardiovascular Research, 63(4), pp. 593-602, 2004. https://doi.org/10.1016/j.cardiores.2004.03.019

[12] Kondo, K., Matsumoto, A., Kurata, H., Tanahashi, H., Koda, H., Amachi, T., Itakura, H. "Inhibition of oxidation of low-density lipoprotein with red wine", The Lancet, 344(8930), p. 1152, 1994. https://doi.org/10.1016/S0140-6736(94)90656-4

[13] Garcia-Alonso, M., Minihane, A.-M., Rimbach, G., RivasGonzalo, J. C., de Pascual-Teresa, S. "Red wine anthocyanins are rapidly absorbed in humans and affect monocyte chemoattractant protein 1 levels and antioxidant capacity of plasma", The Journal of Nutritional Biochemistry, 20(7), pp. 521-529, 2009.

https://doi.org/10.1016/j.jnutbio.2008.05.011

[14] Frankel, E. N., German, J. B., Kinsella, J. E., Parks, E., Kanner, J. "Inhibition of oxidation of human low-density lipoprotein by phenolic substances in red wine", The Lancet, 341(8843), pp. 454-457, 1993. https://doi.org/10.1016/0140-6736(93)90206-V

[15] Ursini, F., Zamburlini, A., Cazzolato, G., Maiorino, M., Bon, G. B., Sevanian, A. "Postprandial Plasma Lipid Hydroperoxides: A Possible Link Between Diet and Atherosclerosis", Free Radical Biology and Medicine, 25(2), pp. 250-252, 1998. https://doi.org/10.1016/S0891-5849(98)00044-6

[16] Maxwell, S., Cruickshank, A., Thorpe, G. "Red wine and antioxidant activity in serum", The Lancet, 344(8916), pp. 193-194, 1994. https://doi.org/10.1016/S0140-6736(94)92795-2
[17] Whitehead, T. P., Robinson, D., Allaway, S., Syms, J., Hale, A. "Effect of Red Wine Ingestion on the Antioxidant Capacity of Serum", Clinical Chemistry, 41(1), pp. 32-35, 1995.

[18] Kinsella, J., Frankel, E., German, B., Kanner, J., Kinsella, G. J. "Possible mechanisms for the protective role of antioxidants in wine and plant foods", Food Technology, 47(4), pp. 85-89, 1993.

[19] Limón-Pacheco, J., Gonsebatt, M. E. "The role of antioxidants and antioxidant-related enzymes in protective responses to environmentally induced oxidative stress", Mutation Research / Genetic Toxicology and Environmental Mutagenesis, 674(1-2), pp. 137147, 2009.

https://doi.org/10.1016/j.mrgentox.2008.09.015

[20] Brambilla, D., Mancuso, C., Scuderi, M. R., Bosco, P., Cantarella, G., Lempereur, L., Di Benedetto, G., Pezzino, S., Bernardini, R. "The role of antioxidant supplement in immune system, neoplastic, and neurodegenerative disorders: a point of view for an assessment of the risk / benefit profile", Nutrition Journal, 7(29), pp. 1-9, 2008. https://doi.org/10.1186/1475-2891-7-29

[21] Brenna, O. V., Pagliarini, E. "Multivariate Analysis of Antioxidant Power and Polyphenolic Composition in Red Wines", Journal of Agricultural and Food Chemistry, 49(10), pp. 4841-4844, 2001. https://doi.org/10.1021/jf0104376

[22] Rossetto, M., Vanzani, P., Zennaro, L., Mattivi, F., Vrhovsek, U., Scarpa, M., Rigo, A. "Stable Free Radicals and Peroxyl Radical Trapping Capacity in Red Wines", Journal of Agricultural and Food Chemistry, 52(20), pp. 6151-6155, 2004. https://doi.org/10.1021/jf0493829

[23] Tedesco, I., Luigi Russo, G., Nazzaro, F., Russo, M., Palumbo, R. "Antioxidant effect of red wine anthocyanins in normal and catalase-inactive human erythrocytes", The Journal of Nutritional Biochemistry, 12(9), pp. 505-511, 2001. https://doi.org/10.1016/S0955-2863(01)00164-4

[24] Ghiselli, A., Serafini, M., Natella, F., Scaccini, C. "Total antioxidant capacity as a tool to assess redox status: critical view and experimental data", Free Radical Biology and Medicine, 29(11), pp. 1106-1114, 2000. https://doi.org/10.1016/S0891-5849(00)00394-4

[25] Ottolenghi, A. "Interaction of ascorbic acid and mitochondrial lipides", Archives of Biochemistry and Biophysics, 79, pp. 355-363, 1959.

https://doi.org/10.1016/0003-9861(59)90414-X

[26] Kikuzaki, H., Nakatani, N. "Antioxidant Effects of Some Ginger Constituents", Journal of Food Science, 58(6), pp. 1407-1410, 1993. https://doi.org/10.1111/j.1365-2621.1993.tb06194.x

[27] Fogliano, V., Verde, V., Randazzo, G., Ritieni, A. "Method for Measuring Antioxidant Activity and Its Application to Monitoring the Antioxidant Capacity of Wines", Journal of Agricultural and Food Chemistry, 47(3), pp. 1035-1040, 1999. https://doi.org/10.1021/jf980496s

[28] Larrauri, J. A., Sánchez-Moreno, C., Rupérez, P., Saura-Calixto, F. "Free Radical Scavenging Capacity in the Aging of Selected Red Spanish Wines", Journal of Agricultural and Food Chemistry, 47(4), pp. 1603-1606, 1999. https://doi.org/10.1021/jf980607n 
[29] Alonso, Á. M., Domínguez, C., Guillén, D. A., Barroso, C. G. "Determination of Antioxidant Power of Red and White Wines by a New Electrochemical Method and Its Correlation with Polyphenolic Content", Journal of Agricultural and Food Chemistry, 50(11), pp. 3112-3115, 2002. https://doi.org/10.1021/jf0116101

[30] Tubaro, F., Rapuzzi, P., Ursini, F. "Kinetic analysis of antioxidant capacity of wine", BioFactors, 9(1), pp. 37-47, 1999. https://doi.org/10.1002/biof.5520090106

[31] Tubaro, F., Micossi, E., Ursini, F. "The antioxidant capacity of complex mixtures by kinetic analysis of crocin bleaching inhibition", Journal of the American Oil Chemists' Society, 73(2), pp. 173-179, 1996. https://doi.org/10.1007/BF02523891

[32] Gardner, P. T., McPhail, D. B., Crozier, A., Duthie, G. G. "Electron spin resonance (ESR) spectroscopic assessment of the contribution of quercetin and other flavonols to the antioxidant capacity of red wines", Journal of the Science of Food and Agriculture, 79(7), pp. 1011-1014, 1999.

https://doi.org/10.1002/(SICI)1097-0010(19990515)79:7<1011::AIDJSFA320>3.0.CO;2-Y

[33] Caldwell, C. R. "Oxygen Radical Absorbance Capacity of the Phenolic Compounds in Plant Extracts Fractionated by HighPerformance Liquid Chromatography", Analytical Biochemistry, 293(2), pp. 232-238, 2001.

https://doi.org/10.1006/abio.2001.5134

[34] Ursini, F., Maiorino, M., Sevanian, A. "Membrane hydroperoxides", In: Sies, H. (ed.) Oxidative stress: Oxidants and Antioxidants, 2nd ed., Academic Press, London, United Kingdom, 1991, pp. 319-336.

[35] Cadenas, E. "Basic mechanisms of antioxidant activity", BioFactors, 6(4), pp. 391-397, 1997.

https://doi.org/10.1002/biof.5520060404

[36] Tubaro, F., Ghiselli, A., Rapuzzi, P., Maiorino, M., Ursini, F. "Analysis of Plasma Antioxidant Capacity by Competition Kinetics", Free Radical Biology and Medicine, 24(7-8), pp. 1228-1234, 1998. https://doi.org/10.1016/S0891-5849(97)00436-X

[37] Airado-Rodríguez, D., Durán-Merás, I., Galeano-Díaz, T., Wold, J. P. "Front-face fluorescence spectroscopy: A new tool for control in the wine industry", Journal of Food Composition and Analysis, 24(2), pp. 257-264, 2011. https://doi.org/10.1016/j.jfca.2010.10.005
[38] Saad, R., Bouveresse, D. J.-R., Locquet, N., Rutledge, D. N. "Using $\mathrm{pH}$ variations to improve the discrimination of wines by 3D front face fluorescence spectroscopy associated to Independent Components Analysis", Talanta, 153, pp. 278-284, 2016. https://doi.org/10.1016/j.talanta.2016.03.023

[39] Bors, W., Michel, C., Saran, M. "Inhibition of the bleaching of the carotenoid crocin a rapid test for quantifying antioxidant activity", Biochimica et Biophysica Acta (BBA) / Lipids and Lipid Metabolism, 796(3), pp. 312-319, 1984. https://doi.org/10.1016/0005-2760(84)90132-2

[40] Singleton, V. L., Rossi, J. A. "Colorimetry of Total Phenolics with Phosphomolybdic-Phosphotungstic Acid Reagents", American Journal of Enology and Viticulture, 16(3), pp. 144-158, 1965. [online] Available at: http://www.ajevonline.org/content/16/3/144 [Accessed: 13 February 2018]

[41] Zoecklein, B. W., Fugelsang, K. C., Gump, B. H., Nury, F. S. "Wine Analysis and Production", 1st ed., Aspen Publishers, Gaithersburg, Maryland, USA, 1999.

[42] Stratil, P., Kubáň, V., Fojtová, J. "Comparison of the Phenolic Content and Total Antioxidant Activity in Wines as Determined by Spectrophotometric Methods", Czech Journal of Food Sciences, 26(4), pp. 242-253, 2005. https://doi.org/10.17221/1119-CJFS

[43] Staško, A., Brezová, V., Mazúr, M., Čertík, M., Kaliňák, M., Gescheidt, G. "A comparative study on the antioxidant properties of Slovakian and Austrian wines", LWT - Food Science and Technology, 41(10), pp. 2126-2135, 2008. https://doi.org/10.1016/j.1wt.2007.11.021

[44] Fernández-Pachón, M. S., Villaño, D., García-Parrilla, M. C., Troncoso, A. M. "Antioxidant activity of wines and relation with their polyphenolic composition", Analytica Chimica Acta, 513(1), pp. 113-118, 2004. https://doi.org/10.1016/j.aca.2004.02.028

[45] Tuberoso, C. I. G., Serreli, G., Congiu, F., Montoro, P., Fenu, M. A. "Characterization, phenolic profile, nitrogen compounds and antioxidant activity of Carignano wines", Journal of Food Composition and Analysis, 58, pp. 60-68, 2017. https://doi.org/10.1016/j.jfca.2017.01.017

[46] Di Majo, D., La Guardia, M., Giammanco, S., La Neve, L., Giammanco, M. "The antioxidant capacity of red wine in relationship with its polyphenolic constituents", Food Chemistry, 111(1), pp. 45-49, 2008.

https://doi.org/10.1016/j.foodchem.2008.03.037 